\title{
Pressure and volume changes during the first breath of human neonates
}

\author{
A. D. MILNER AND R. A. SAUNDERS \\ From the Department of Child Health, University of Nottingham, and Nottingham City Hospital Maternity \\ Unit
}

SUMMARY The pressure and volume changes associated with the first breath were measured in 17 healthy term babies, using oesophageal balloons and a reverse plethysmograph. 5 babies expanded their lungs with less than $-20 \mathrm{cmH}_{2} \mathrm{O}(-2 \mathrm{kPa})$. The characteristic opening pressure pattern previously described was seen in only one baby, whose initial volume change was an expiratory one. It is concluded that opening pressures greater than $10 \mathrm{cmH}_{2} \mathrm{O}(0.98 \mathrm{kPa})$ are rarely seen in term healthy infants.

Calculations based on the anatomical dimensions of the human lung at birth and the surface tension properties of plasma suggested that a transpulmonary pressure of $20 \mathrm{cmH}_{2} \mathrm{O}(1.96 \mathrm{kPa})$ would be required before any gaseous lung volume change occurred (Avery and Mead, 1959). This concept of an 'opening pressure' has been supported by pressure/volume studies on isolated lung preparations from babies dying before or soon after delivery (Agostini, 1959; Gribetz et al., 1959; Gruenwald, 1963; Rosen and Laurence, 1965).

Karlberg and his colleagues measured the volume and pressure changes occurring during the first breath in 11 spontaneously breathing babies (Geubelle et al., 1959; Karlberg et al., 1962). Of these, 5 showed a pattern of lung expansion suggesting that there was an opening pressure, the baby producing a negative intrathoracic pressure of up to $50 \mathrm{cmH}_{2} \mathrm{O}$ $(4.9 \mathrm{kPa})$ before any air entered the lung. $A$ further 5 , however, did not show this phenomenon but started lung expansion as soon as the oesophageal pressure started to fall. Karlberg and his colleagues suggested that this might be achieved by a form of 'frog breathing' or a capillary erectile mechanism. They also noticed that some babies expanded their lungs without any apparent respiratory effort. They surmised that this was achieved by passive recoil of the thorax after the compression effect of the passage down the birth canal. However, there is little evidence to support the concept of frog breathing in the human neonate, and the increase in pulmonary blood flow appears to follow, rather than precede, lung expan-

Received 29 April 1977 sion (Dawes et al., 1953; Enhörning et al., 1966). Avery and her colleagues (Avery et al., 1959) showed that pulmonary vascular distension did lead to a small fall in intratracheal pressure in excised lungs, but also considered that the effect is too small to initiate lung expansion.

Clinical observations on babies born in the labour suite strongly suggest that most manage to expand their lungs without the degree of chest wall recession that would be expected if large intrathoracic pressure changes were occurring. In view of these inconsistencies we repeated the studies of Karlberg et al. (1962; Karlberg and Koch, 1962), measuring the pressure and volume changes associated with the first breath in a group of healthy term babies.

\section{Method}

Apparatus. The volume changes were measured by a reverse plethysmograph consisting of a rigid 100 litre container (Fig. 1). Using a container of this size, the back pressure produced by a volume change of $70 \mathrm{ml}$ would be less than $1 \mathrm{cmH}_{2} \mathrm{O}(0.098 \mathrm{kPa})$, after allowing for the adiabatic effect. The reverse plethysmograph was connected to a modified opaque BOC face mask by two tubes with internal diameters of $20 \mathrm{~mm}$ and $7 \mathrm{~mm}$ respectively. A type 1 Fleisch pneumotachograph was mounted in the wide-bore tube so that flow could also be measured. $A$ fan was attached to the narrow tube to achieve a free flow of air $(0.05 \mathrm{l} / \mathrm{s})$ round the circuit to minimize rebreathing. The relative resistances of the two tubes was such that less than $1.5 \%$ of any volume change would be conducted down the narrow tube and 


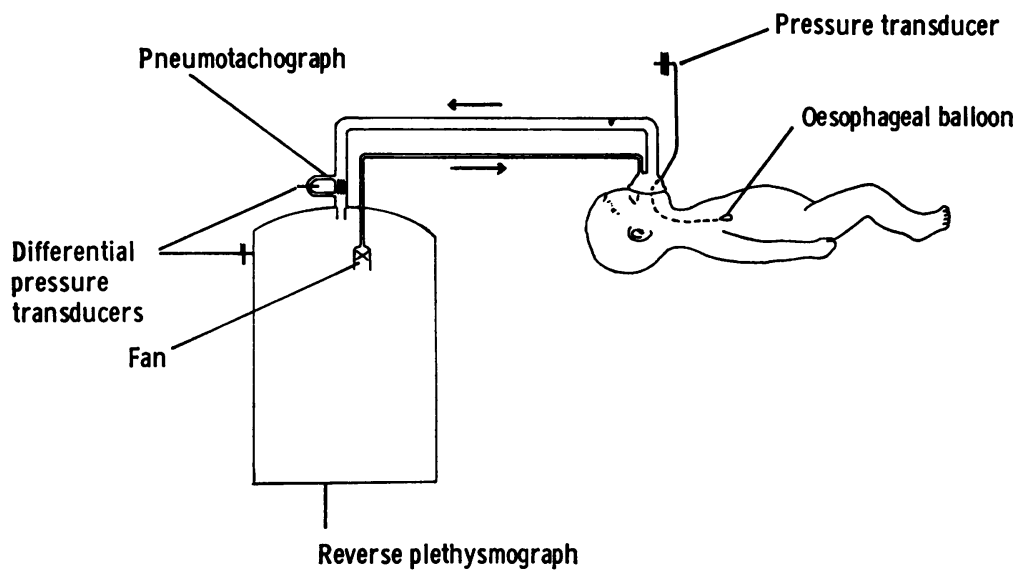

Fig. 1 Diagrammatic representation of the reverse plethysmograph system. Lung volume changes were recorded by the effect on pressure in a 100 litre rigid container, oesophageal pressure changes by a balloon, catheter, and transducer, and flow by a pneumotachograph. Rebreathing was minimized by continuous circulation of system air across the face mask.

bypass the pneumotachograph (Fig. 1). Intrathoracic pressure changes were monitored using a soft latex balloon $(35 \mathrm{~mm} \times 7 \mathrm{~mm})$, mounted on a 5FG feeding tube which passed through an airtight grommet in the hub of the face mask. The oesophageal balloon was connected to a strain gauge pressure transducer (SE Labs, SEM 4.86). The pressure changes in the plethysmograph and the pressure across the pneumotachograph were measured with Elema Schönander differential pressure transducers (EMT $32 \mathrm{C}$ ). All signals were relayed via an amplification system (SE Labs, EMMA) to a 4-channel FM tape recorder (SE Labs 84).

The oesophageal balloon transducer was calibrated against a water column at the end of each run. The pneumotachograph was calibrated using a rotameter. The reverse plethysmograph was calibrated by injecting and withdrawing known volumes in and out of the sealed system at approximately the baby's spontaneous breathing rate, to reduce error from the adiabatic effect.

The data were analysed in two ways. The output of the tape recorder was fed to a 6-channel 6" recorder with ultraviolet-sensitive paper (SE Labs, SE3006). The pressure and volume signals were also fed onto an XY plotter (SE Labs, SE225 mark II), playing at $25 \%$ of the recording speed, so that pressure/volume curves of the first breath could be constructed.

The $63 \%$ rise time of the oesophageal balloon system was assessed by sudden compression, achieved by bursting an inflated rubber balloon within a sealed chamber. This gave a value of $6 \cdot 8 \mathrm{~m} / \mathrm{s}$. This is equivalent to a damping of $3 \mathrm{db} /$ octave at $23.4 \mathrm{~Hz}$. The rise time of the reverse plethysmograph, assessed by measuring the pressure change produced by bursting a rubber balloon in a chamber attached to the face mask, was $30 \mathrm{~m} / \mathrm{s}$, equivalent to a $3 \mathrm{db} /$ octave attenuation at $5 \cdot 3 \mathrm{~Hz}$. These characteristics led to an electromechanical phase lag of volume behind pressure of $8 \cdot 3^{\circ}$ at a typical breathing frequency of 60 per minute.

The dynamic response of the XY plotter was $\mathbf{0 . 7}$ $\mathrm{Hz}$ with a pen speed of $300 \mathrm{~m} / \mathrm{s}$. These values were improved by $400 \%$ by replaying the tape-recorded signals at $25 \%$ of the recording speed. All amplifiers and transducers were unconditionally stable over many hours and observed baseline changes over several minutes were undetectable. The balloon was equally stable, but the very small pressure changes being measured in the reverse plethysmograph rendered the volume record subject to thermal drift when the apparatus was taken from one room to another at a different temperature. This effect was variable, but was partly remedied during the study period by attaching the 'indifferent' limb of the differential transducer to a closed container of similar size to the plethysmograph. Where thermal drift did obtrude (Fig. 6) it was linear over the observed range and identical when the baby was disconnected and the mask covered, and could therefore be allowed for by construction of a 'drift line' on the volume/ time trace.

To check for leakage $50 \mathrm{ml}$ increments and decrements were applied to the plethysmograph with the mask in place on two occasions with typical configurations, though it was impracticable to do this on each infant measured. In both cases the changes in the plateaux produced were indistinguishable from the thermal drift and so, though 5 of the babies inspired larger volumes than this, the system was considered satisfactorily leakproof at the working pressures.

Technique. Delivery of each baby was carried out by the unit midwives, with the mothers lying supine. 
Once the baby's body had been delivered, the baby was placed on his back, between his mother's legs. The oesophageal balloon was passed through the baby's mouth so that it lay in the lower third of the oesophagus. In a previous study (Milner et al., 1977a) we found that this positioning is achieved when the balloon is passed $13 \mathrm{~cm}$ beyond the lips of term babies. As the oesophageal balloon was descending, the soft latex rubber face mask was lowered over the baby's nose and mouth achieving an air-tight seal. Throughout the measurements, a stethoscope was used to monitor the heart rate. If this fell below 100 beats $/ \mathrm{min}$, the procedure was immediately abandoned and the baby stimulated to breathe and, if necessary, intubated. While measurements were being collected the midwife clamped and cut the umbilical cord. Measurements were continued for up to 60 seconds. The baby was then dried, wrapped in a towel, and handed to the mother. Informed maternal and, where possible, paternal consent was always obtained early in labour. The project was considered and passed by the North Nottingham Ethical Committee.

\section{Results}

Measurements of first breaths were attempted on 127 occasions, but were successful on only 17 . By far the commonest reason for failure was that the baby started breathing immediately after delivery. On three occasions the babies were slow to initiate respiration and the procedure was abandoned. 2 of these babies cried immediately on skin stimulation and the third required intubation.

Full analysis was not possible on all 17 records. The biggest problem arose from oesophageal contractions, presumably stimulated by the presence of the oesophageal balloon. Where the trace was unsatisfactory the pressure measurements were excluded.

Inspiratory pressure changes were relatively small (Table), only $5.4 \mathrm{cmH}_{2} \mathrm{O}(0.53 \mathrm{kPa})$ to $38.4 \mathrm{cmH}_{2} \mathrm{O}$ (3. $76 \mathrm{kPa})$ mean $22.7 \mathrm{cmH}_{2} \mathrm{O}(2 \cdot 20 \mathrm{kPa})$. Pressures associated with expiration were high, mean 49.1 $\mathrm{cmH}_{2} \mathrm{O}(4 \cdot 81 \mathrm{kPa})$, range 0-92 $\mathrm{cmH}_{2} \mathrm{O}(0-9.02 \mathrm{kPa})$, but a change in initial functional residual capacity (FRC) of $30 \mathrm{ml}$ was observed in one baby without any active expiratory effort. The initial inspiratory volumes ranged from 13.4 to $90 \mathrm{ml}$ (mean $44.6 \mathrm{ml}$ ). Only one of 17 babies failed to establish an FRC by the end of the first breath, the mean resting volume changing by $15.3 \mathrm{ml}$ (range $0-32.0 \mathrm{ml}$ ). This baby achieved a small resting lung volume on the second breath $(5.6 \mathrm{ml})$.

The time relationships of the pressure and volume changes in each breath were examined by analysis
Table Individual values of oesophageal pressure (Poes) during the first inspiration (insp) and first expiration (exp), the related inspiratory volume of the first breath ( $V$ insp), and the volume remaining in the lungs at the end of the first breath ('initial functional residual capacity', FRC). Volume data were obtained on 17 babies, but pressure data on only the first 13 listed

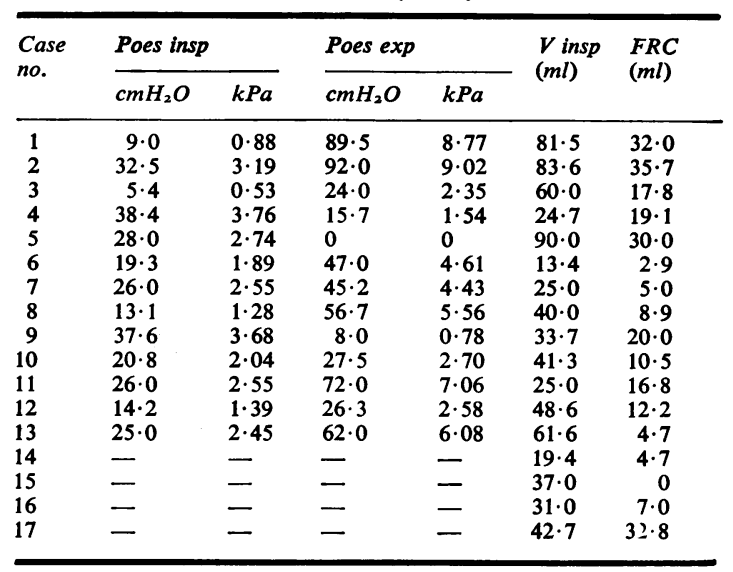

of the longitudinal traces from the U-V recorder, and of the pressure/volume loops. In 5 babies inspiration started as soon as the intrathoracic pressure fell (Figs. 2 and 3). This was not related to the size of the peak inspiratory pressure, which ranged from -5.4 to $-38.4 \mathrm{cmH}_{2} \mathrm{O}(-0.53$ to $-3.76 \mathrm{kPa})$. In a further 5 babies there was a small fall in oesophageal pressure, -5 to $-10 \mathrm{cmH}_{2} \mathrm{O}(-0.49$ to $-0.98 \mathrm{kPa})$, before inspiration started (Fig. 4). In 2 babies analysis of the pressure/volume loops suggested that there was an opening pressure of approximately -20 $\mathrm{cmH}_{2} \mathrm{O}(-2 \mathrm{kPa})$. However, close examination of the longitudinal trace suggested that the appearance was the result of rapid unsustained inspiratory gasps, and did not closely mimic the pattern reported by Karlberg et al. (1962) (Fig. 5). One baby did show the typical opening pressure pattern, but he was unusual in that his first volume change was expiratory, rather than inspiratory (Fig. 6).

\section{Discussion}

The inspiratory volume changes associated with the first breath were very similar to those previously reported by Karlberg et al. (1962). These workers noted the formation of a gaseous FRC in only 7 of their 11 babies. In our series all except one baby achieved a gaseous residual volume at the end of the first expiration, and even this infant retained $5 \mathrm{ml}$ of his second breath.

Although peak inspiratory pressures were sometimes high, up to $-38.4 \mathrm{cmH}_{2} \mathrm{O}(-3.76 \mathrm{kPa}), 5$ of 


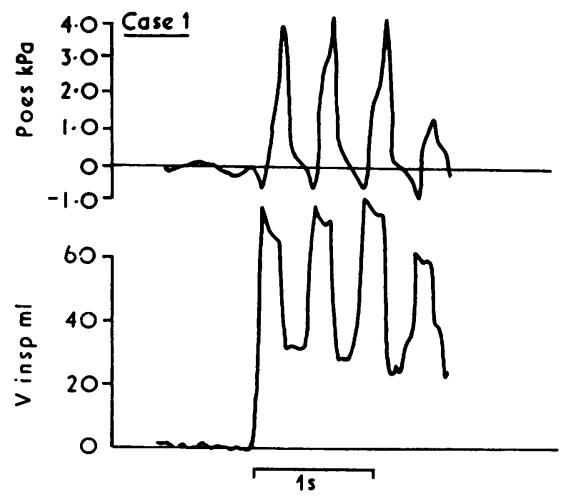

$\underline{A}$
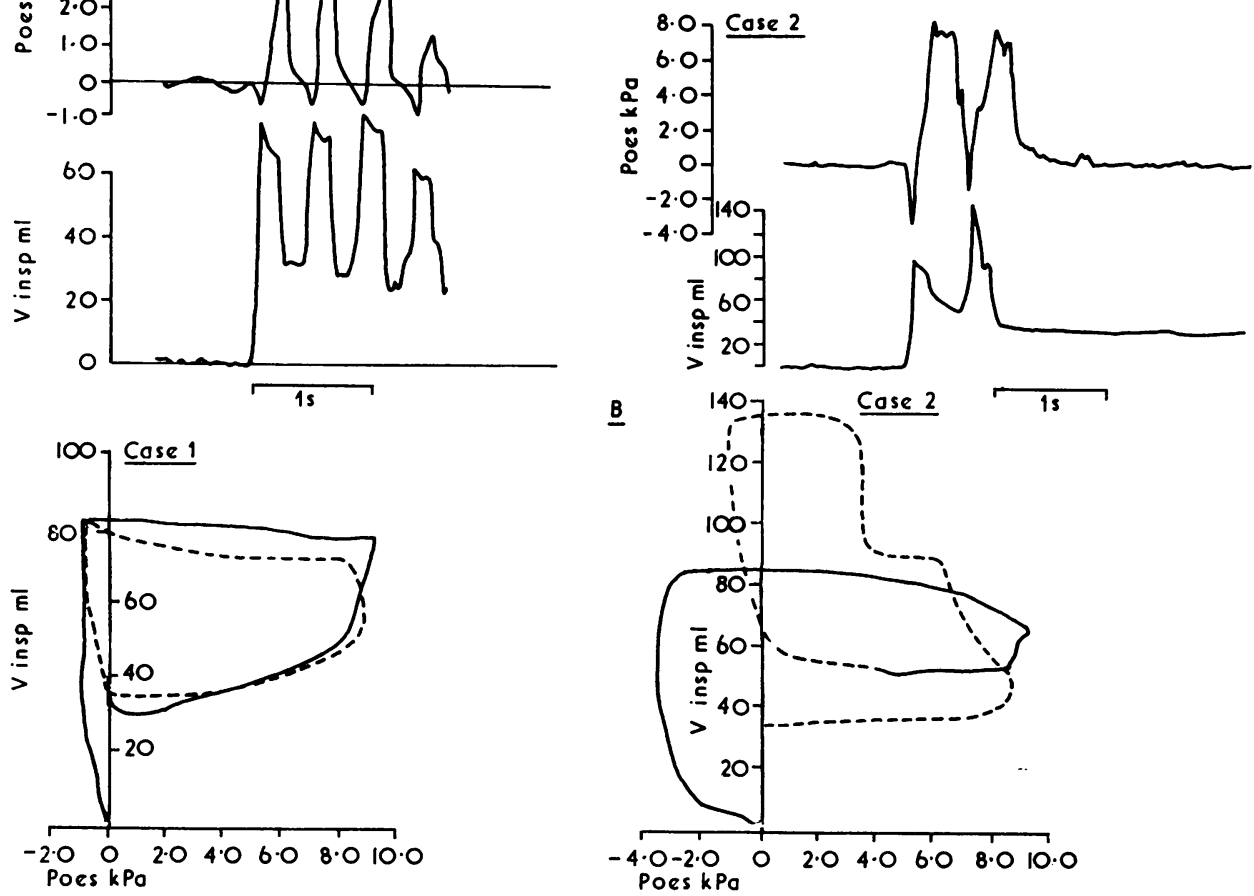

Fig. 2 (A) Pressure (Poes) and volume ( $V$ insp) traces plotted against time on 2 infants, to illustrate the wave forms produced. (Time plotted from left to right.) (B) $X$-Y plots of pressure against volume in the same 2 infants, showing an immediate volume change associated with the initial pressure change (absence of an 'opening pressure'). In these and subsequent $X-Y$ plots the first breath is represented by a solid line, the second by a dashed line, and the third by a dotted line. In contrast to Karlberg's diagrams, pressure is plotted conventionally on the abscissa, i.e. negative to the left and positive to the right. Conversion: SI to traditional units-Pressure: $1 \mathrm{kPa} \approx 10 \cdot 2 \mathrm{cmH}_{2} \mathrm{O}$.

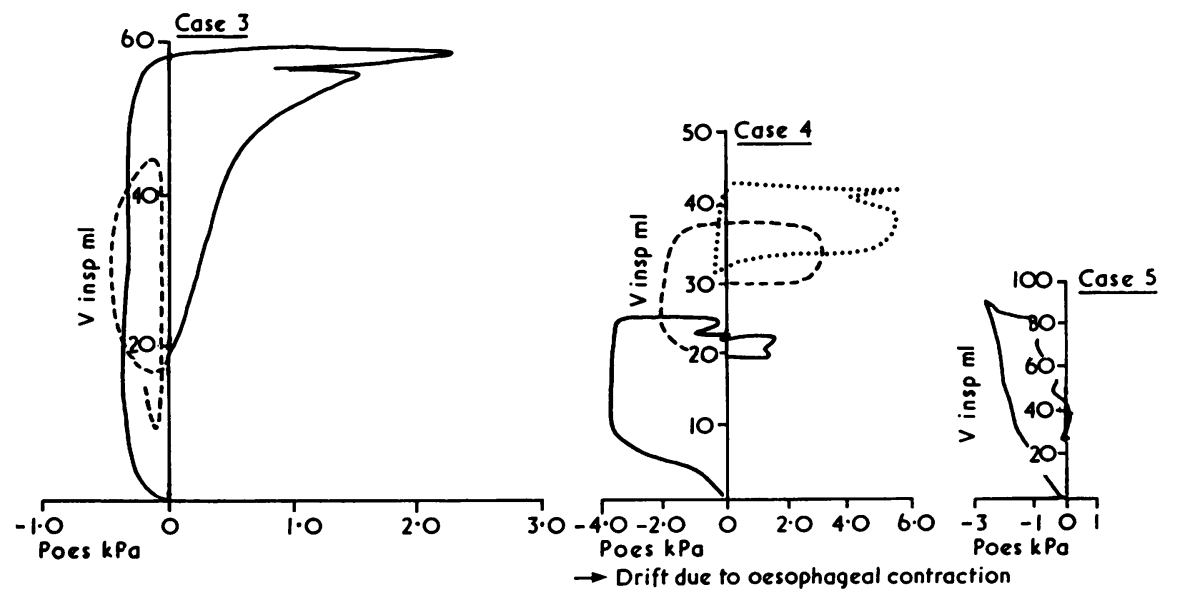

Fig. $3 X$-Y plots of pressure against volume of 3 further infants, again showing an immediate change in volume with the initial pressure change. 

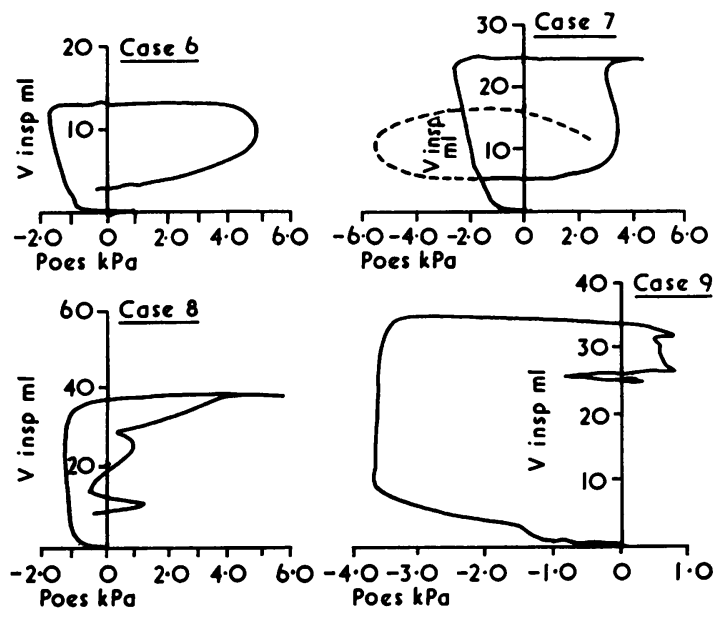

Fig. $4 X$-Y plots of pressure against volume on 4 of the 5 infants who showed small 'opening pressures' of less than $-1 \mathrm{kPa}\left(-10 \mathrm{~cm} \mathrm{H}_{2} \mathrm{O}\right)$ during the first breath. the 13 fully documented babies expanded their lungs with less than $-20 \mathrm{cmH}_{2} \mathrm{O}(-2 \mathrm{kPa})$, and 4 with less than $-15 \mathrm{cmH}_{2} \mathrm{O}(-1.5 \mathrm{kPa})$. One explanation for these relatively low pressures is that the oesophageal pressure system was under-recording the intrathoracic pressure swings. We are convinced that this was not the case, for the following reasons. (1) Using identical oesophageal balloons we have measured lung function on over 300 occasions in healthy and sick neonates, and obtained data which correlate well with previously published material (Cook et al., 1957; Swyer et al., 1960; Karlberg and Koch, 1962; Dahms et al., 1974; Saunders et al., 1976; Milner et al., 1977a, b). (2) Some of the babies who exhibited small inspiratory pressures on initial lung expansion, produced large negative pressure swings associated with crying in subsequent breaths. (3) All except one of the babies had high, positive, intrathoracic pressure swings on the first expiration, up to $+92 \mathrm{cmH}_{2} \mathrm{O}(+9.02 \mathrm{kPa})$, even when the initial inspiratory pressure changes were small. Case 1 illustrates this point well (Fig. 2). It is possible
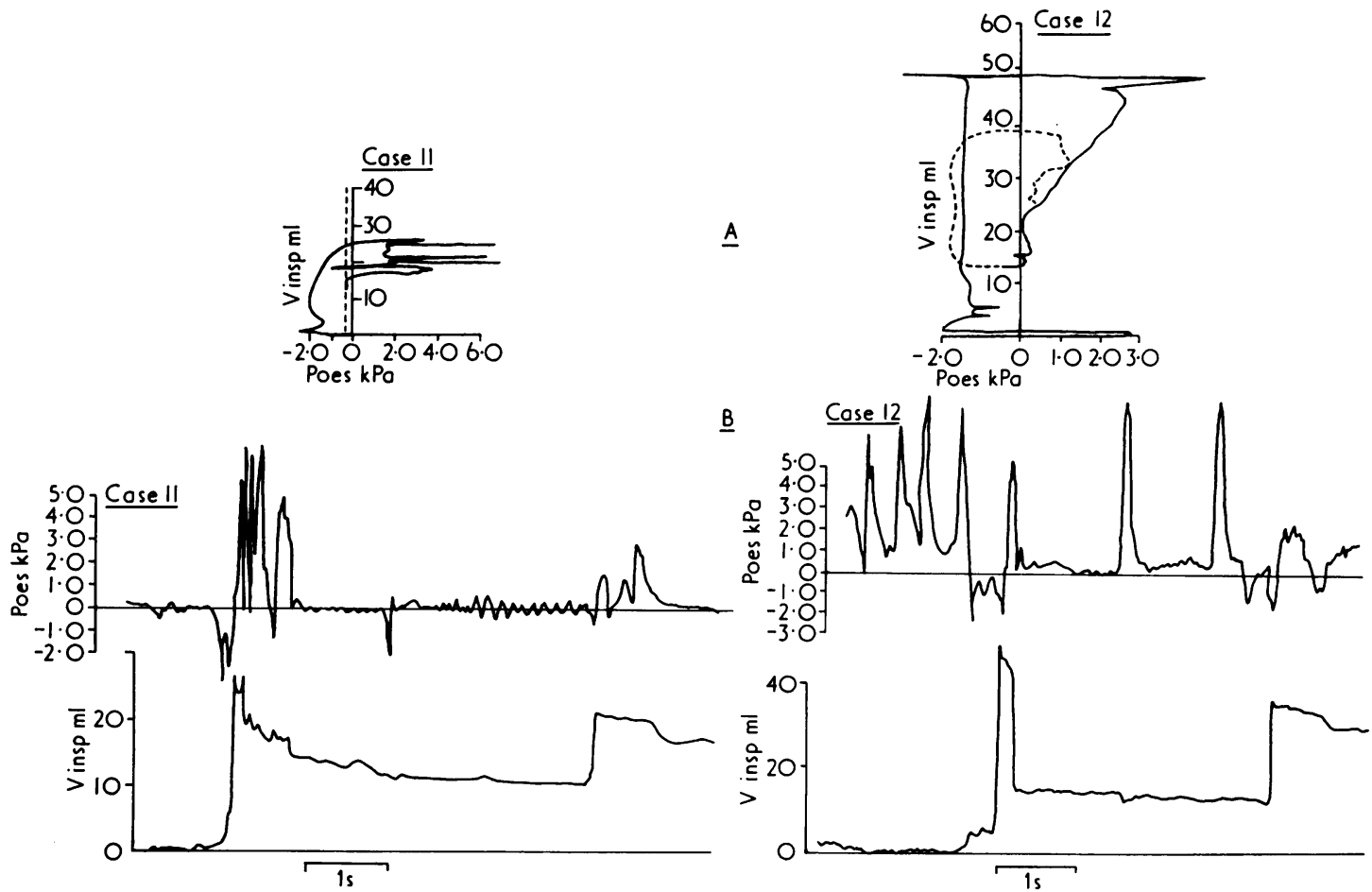

Fig. 5 (A) $X$-Y plots on 2 infants showing an apparent 'opening pressure' in excess of $-2 \mathrm{kPa}\left(-20 \mathrm{cmH} \mathrm{H}_{2} \mathrm{O}\right)$. $(B)$ Longitudinal traces on the same infants show that these are rapid, short-duration pressure spikes superimposed upon inspiratory pressures. 

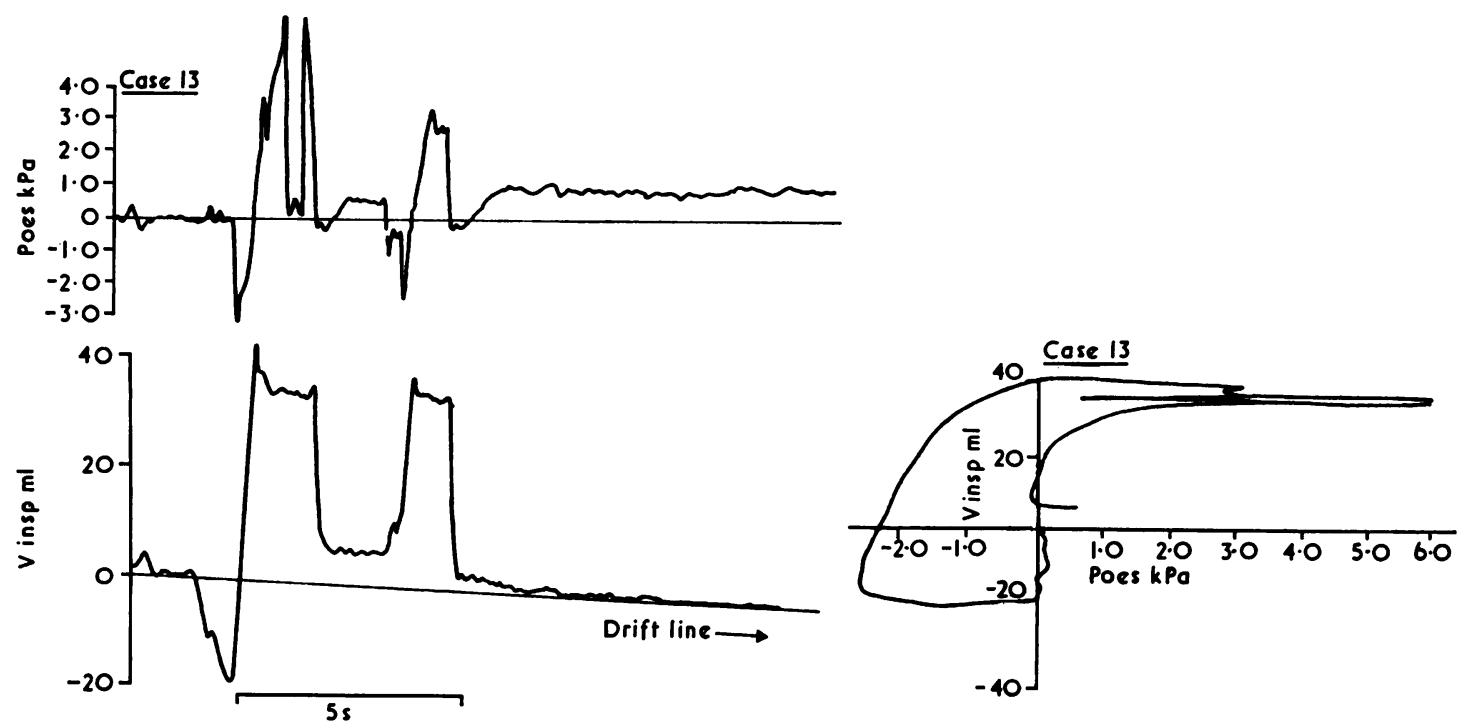

Fig. 6 Longitudinal and $X$-Y plots on the one infant who did show an 'opening pressure' exceeding $-2 \mathrm{kPa}\left(-2 \mathrm{O} \mathrm{cmH}_{2} \mathrm{O}\right)$. This infant was unique in that his first post-partum volume change was an expiratory one. This change in volume was not accompanied by a corresponding net shift in oesophageal pressure. The baseline volume drift was due to thermal changes within the plethysmograph. The positive pressure after the second breath probably represents a Valsalva manoeuvre, since the pressure returned to the initial baseline after the third breath.

to have selective damping of negative pressure deflections if the balloon is over-expanded. In our technique the balloon was almost fully collapsed, containing only $0.15 \mathrm{ml}$ of air, ensuring that its compliance was at a maximum (Milner et al., 1977a). In this configuration, pressure measurement was within $1 \%$ linearity between -245 and $+185 \mathrm{cmH}_{2} \mathrm{O}$ $(-24.0$ and $+18.0 \mathrm{kPa})$.

In fact our peak inspiratory pressures do not differ greatly from those reported by Karlberg et al. (1962). They considered that high, negative, intrathoracic pressures represented the normal pattern and offered explanations for those babies who achieved lung expansion with less effort. However, we suggest that although inspiratory pressures may be large the majority of babies begin ventilation with lower pressures than are generally accepted.

High expiratory pressures were measured, again very similar to those reported by Karlberg, and it may be that these pressures aid the clearance of lung fluid and lead to a more even distribution of air throughout the lung. Interestingly, the one baby who did not show any positive expiratory pressure achieved an FRC of $30 \mathrm{ml}$, indicating that, although usually present, a high positive pressure on expiration was not essential for the formation of FRC.

Analysis of pressure/volume loops of the first breath was also of considerable interest to us. One problem associated with this analysis was the identification of the resting or 'zero' pressure, as the base line pressure after the first breath was often slightly different from the resting pressure before ventilation had started. For the sake of uniformity, we have selected the initial pressure as the 'zero' reference point.

Only one trace showed the typical opening pressure pattern described by Karlberg et al. (1962). 2 further babies had inflation patterns which, it could be argued, showed opening pressures of approximately $-20 \mathrm{cmH}_{2} \mathrm{O}(-2 \mathrm{kPa})$. However, careful examination of the longitudinal traces indicated that both these babies made initial rapid inspiratory efforts which were not sustained and were probably brief gasps. These were followed by more typical inspiratory pressure changes (Fig. 5), and neither showed the classical opening pressure profile. The remaining babies either had no opening pressure, the lungs starting to expand as soon as the oesophageal pressure began to fall, or an opening pressure of less than $-10 \mathrm{cmH}_{2} \mathrm{O}(-1 \mathrm{kPa})$. There was no relationship between the presence or absence of an opening pressure and the magnitude of the inspiratory effort.

Again our data are not very different from those of Karlberg et al. (1962), who found an opening pressure in only 5 of 11 babies. These babies were slower to initiate spontaneous breathing than ours, taking 
up to 90 seconds. It may be that opening pressures occur more frequently in babies who have a degree of asphyxia. An alternative explanation for the rarity of the opening pressure pattern is that there was a large, negative, intrathoracic pressure before the first inflation, perhaps resulting in a transpulmonary pressure gradient approaching $20 \mathrm{cmH}_{2} \mathrm{O}$ $(2 \mathrm{kPa})$. We consider this to be most unlikely, in view of the absence of chest wall recession and the fact that the resting oesophageal pressure did not rise dramatically once lung expansion had occurred. Karlberg et al. (1962) also considered that the resting oesophageal pressure was close to atmospheric before the first breath. Neither can phase lag between the signals explain the shape of the pressure/volume loops, since the volume trace signal lagged slightly behind the oesophageal pressure, rather than leading it. This would have tended to exaggerate, rather than hide, an opening pressure pattern.

The one baby who did show the classical opening pressure was also unique in our series in that his initial volume change was an expiratory one (Fig. 6). This volume change was not accompanied by any shift in oesophageal pressure baseline. Close scrutiny of the volume trace and flow trace (not illustrated) confirmed that this could only have represented a genuine change in lung volume and was not due to leakage of thermal drift. We are not certain of the significance of this paradoxical finding, but Karlberg et al. (1962) also reported this phenomenon in their study.

We have not in our study evaluated the significance of elastic chest recoil at birth in aiding lung expansion, but a further study is nearing completion of this aspect by means of a mask and catheter applied to the baby before delivery of the thorax.

Many healthy term babies can expand their lungs with lower pressures than are generally accepted, and although the first expiration is usually accompanied by high, positive, intrathoracic pressure, this is not essential for the formation of a gaseous residual volume, and unlike the isolated lung preparation, the lungs of the healthy neonate rarely show an opening pressure of more than $10 \mathrm{cmH}_{2} \mathrm{O}(0.98 \mathrm{kPa})$.

We are grateful to Action Research for the Crippled Child for financing this project.

\section{References}

Agostini, E. (1959). Volume-pressure relationships of the thorax and the lung in the newborn. Journal of Applied Physiology, 14, 909-913.
Avery, M. E., and Mead, J. (1959). Surface properties in relation to atelectasis and hyaline membrane disease. American Journal of Diseases of Children, 97, 517-523.

Avery, M. E., Frank, N. R., and Gribetz, I. (1959). The inflationary force produced by pulmonary vascular distention in excised lungs. The possible relation of this force to that needed to inflate the lungs at birth. Journal of Clinical Investigation, 38, 456-462.

Cook, C. D., Sutherland, J. M., Segal, S., Cherry, R. B., Mead, J., McIlroy, M. B., and Smith, C. A. (1957). Studies of respiratory physiology in the newborn infant. III. Measurements of the mechanics of respiration. Journal of Clinical Investigation, 36, 440-448.

Dahms, B. B., Krauss, A. N., and Auld, P. A. M. (1974). Pulmonary function in dysmature infants. Journal of Pediatrics, 84, 434-437.

Dawes, G. S., Mott, J. C., Widdicombe, J. G., and Wyatt, D. G. (1953). Changes in the lungs of the newborn lamb. Journal of Physiology, 121, 141-162.

Enhörning, G., Adams, F. H., and Norman, A. (1966). Effect of lung expansion on the fetal lamb circulation. Acta Paediatrica Scandinavica, 55, 441-451.

Geubelle, F., Karlberg, P., Koch, G., Lind, J.. Wallgren, G., and Wegelius, C. (1959). L'aération du poumon chez le nouveau-né. Biologia Neonatorum, 1, 169-210.

Gribetz, I., Frank, N. R., and Avery, M. E. (1959). Static volume-pressure relations of excised lungs of infants with hyaline membrane disease, newborn and stillborn infants. Journal of Clinical Investigation, 38, 2168-2175.

Gruenwald, P. (1963). Respiratory studies in newborn infants. II. Normal and abnormal expansion of the lungs of newborn infants obtained at autopsy. Opening pressure, maximal volume and stability of expansion. Laboratory Investigation, 12, 563-576.

Karlberg, P., and Koch, G. (1962). Respiratory studies in newborn infants. III. Development of mechanics of breathing during the first week of life. A longitudinal study. Acta Paediatrica, Suppl. 135, 121-129.

Karlberg, P., Cherry, R. B., Escardo, F. E., and Koch, G. (1962). Pulmonary ventilation and mechanics of breathing in the first minutes of life, including the onset of respiration. Acta Paediatrica, 51, 121-136.

Milner, A. D., Saunders, R. A., and Hopkin, I. E. (1977a). Analysis of tidal pressure/volume and flow/volume respiratory loops in human neonates. Clinical Science and Molecular Medicine (in press).

Milner, A. D., Saunders, R. A., and Hopkin, I. E. (1977b). The effects of continuous distending pressure on lung volumes and lung mechanics in the immediate neonatal period. Biology of the Neonate, 31, 111-115.

Rosen, M., and Laurence, K. M. (1965). Expansion pressures and rupture pressures in the newborn lung. Lancet, 2, 721-722.

Saunders, R. A., Milner, A. D., and Hopkin, I. E. (1976). The effects of continuous positive airway pressure on lung mechanics and lung volumes in the neonate. Biology of the Neonate, 29, 178-186.

Swyer, P. R., Reiman, R. C., and Wright, J. J. (1960). Ventilation and ventilatory mechanics in the newborn. Journal of Pediatrics, 56, 612-622.

Correspondence to Dr. A. D. Milner, Department of Child Health, University Hospital and Medical School, Clifton Boulevard, Nottingham NG7 2UH. 